Case 5, Dr. Grace Griffith.-A case of Erythema Iris in a male aged 23 years. The patient gave a history of irritation on the backs of his elbows four days before the rash appeared. At first there were a few spots, and each day he noticed a few more all coming in the same region close to each other. He had had eight attacks in the last three years. The first attack was the worst, and lasted five weeks. All the attacks occurred over the same region. The rash never spread further or attacked other parts of the body, and each attack lasted from two to five weeks. The spots itched and burned at night. $\mathrm{He}$ was in good general health, and gave no history of having had any debilitating illness. He had had recent attacks of pain in his shoulders, which he called muscular rheumatism. He had not had a sore throat recently, and his tongue was not sore. On examination the patient had symmetrical lesions on the extensor surfaces of his arms : most marked about the elbows. The lesions were discreet, circular patches, with pale raised urticarial margins, each surrounding a central macule or papule, or, in older lesions, a dull purplish spot. Examination of his mouth showed no typical lesions on his mucous membrane, but the soft palate and fauces were studded with clear papules, giving them a granular appearance. He had a couple of carious teeth which had ached recently. No other abnormality was found.

Dr. Wigley said he assumed that the erythema iris was more prominent before than it was to-day.

Dr. Grace Griffith replied that the patient's first attack was very much worse, and that each attack since had been less severe.

\title{
REVIEWS.
}

\section{BACTERIAL ENDOCARDITIS.}

By C. Bruce Perry, M.D., with Appendix on "An Experimental Study of Malignant Endocarditis," by D. M. Lloyd-Jones, M.D. John Wright \& Sons, Ltd., Bristol. 1936. Price 10/6.

This volume, which is published by the Trustees of the Harmsworth Memorial Research Fund, provides a very good account of our knowledge up-to-date of the condition variously known as ulcerative endocarditis, malignant endocarditis or endocarditis lenta. We agree with the author that the best title of this disease is " Bacterial Endocarditis," which can be subdivided into acute, subacute and chronic and, if the etiological organism is known this can be substituted for the word "bacterial" in the designation.

Dr. Perry commences his review with a historical survey and follows this up with a discussion of the pathology, the bacteriology, the clinical picture, the therapy and prognosis of the disease. In the discussion of the treatment he shows how unsatisfactory have been any methods hitherto employed, and, stressing the tendency for the condition to be superimposed on a pre-existing cardiac lesion, concludes that it is in prophylaxis and the prevention of rheumatic carditis that our chief hope lies.

The volume concludes with a most interesting appendix by $\mathrm{Dr}$. Jones detailing his attempts, which in many instances were successful, to repeat the disease in the rabbit by intravenous injection of different types of organisms commonly found in the malady.

\section{THE NATURAL HISTORY OF DISEASE.}

By John A. RyLe, M.D., F.R.C.P. Oxford University Press. 1936. Price $15 /-$.

It is a brave undertaking for any medical writer to collect all his papers over a certain period of time and reissue them in one composite volume. We are glad, however, that Prof. Ryle has done this for the result is a most enjoyable and stimulating volume, which reveals the author as a cultured, philosophical, experienced physician with a poet's gift of expression and demonstrates the wisdom of the Crown in calling him to the Professorship of Physic in the University of Cambridge. 